\title{
Vestigios para una historia musical de la sociedad chilena en la historia reciente: El Fondo Documental Sello Alerce
}

\author{
Vestiges for a musical history of Chilean society in recent times: The documentary \\ collection of the Alerce music label
}

\author{
César ALBORNOZ CUEVAS 1 \\ Universidad Católica de Chile, Chile \\ cealborn@uc.cl
}

\section{Resumen}

El sello Alerce fue uno de los más importantes factores en la evolución de la historia de la música popular chilena durante el último cuarto del siglo XX. Su existencia le dio al período de la dictadura de Pinochet y a los inicios de la transición, una imagen sonora registrada en soportes musicales que permite disponer de fuentes para la comprensión de aquel tiempo desde la historia. Este artículo trata sobre la recuperación de sus documentos como patrimonio archivístico nacional, reflexiona sobre cómo se podría comprender nuestra historia reciente desde los vestigios musicales, y devela la historicidad que ofrece un conjunto de síntomas sobre pasado cultural organizados a modo de archivo. Asimismo, este escrito enseña el cómo desde la archivística, en su dimensión más práctica, se recupera, restaura y conserva un archivo musical importante para la historia reciente de Chile.

Palabras clave: Industria musical; fuente; archivo; sello discográfico; historia cultural; documento.

\footnotetext{
1 Este artículo es producto de una investigación financiada por el Fondo FAIP 2016, Proyecto FAIP-N76-INV "La figura de Ricardo García como factor determinante en la industria fonográfica chilena independiente de los últimos cincuenta años". Parte del contenido fue expuesto en la ponencia "Rock chileno: fuentes, archivos y fondos", realizada en el marco del IV Encuentro Iberoamericano de Archivos Musicales y Sonoros, organizada por el Archivo de Música de la Biblioteca Nacional entre el 26 y el 30 de octubre de 2020 .
}

César ALBORNOZ CUEVAS

Vestigios para una historia musical de la sociedad chilena en la historia reciente: El Fondo Documental Sello Alerce Sur y Tiempo. Revista de Historia de América, №4, julio-diciembre 2021, pp. 138-160. 


\begin{abstract}
The Alerce label was one of the most important factors in the evolution of the history of Chilean popular music during the last quarter of the 20th century. Its existence gave to the period of the dictatorship of Pinochet and to the beginnings of the transition a recorded sound image in musical supports, that allows to have sources for the understanding of that time from the history. This article deals with the recovery of its documents as national archival heritage; reflects on how our recent history could be understood from the musical vestiges, and reveals the historicity that offers a set of symptoms about cultural past organized as a file. This paper also shows how, in its most informal dimension, archives are recovered, restored and preserved in an important musical archive for the recent history of Chile.
\end{abstract}

Keywords: Music industry; source; archive; record label; cultural history; document.

\title{
Introducción
}

La historiografía ha considerado la relevancia de la fuente escrita desde su constitución como disciplina profesional. Sin embargo, en las últimas décadas del siglo XX, gracias a revisionismos epistemológicos más constructivos que demoledores, se ha reconocido en su real potencia la calidad de vestigios cuyo mensaje se propone desde distintos formatos y soportes $y$ hacia diferentes capacidades de percepción, no sólo visuales ni racionales. Es así como el mentado giro cultural de alguna forma sistematizó una serie de experiencias prácticas que encontraban en atípicos síntomas de tiempo, como expresiones plásticas o sonoras, fuentes válidas para la disciplina histórica. Desde la década de 1990 en Chile, las fuentes trabajadas no se restringirían al formato escrito; podrían ser sonoras, particularmente musicales.

Esto implicó que una disciplina paralela y complementaria como la archivística, se preocupara también del documento musical como objeto de elaboración profesional. Fue así que se fueron consolidando como instancias: el Archivo Sonoro de Música Tradicional Chilena (AMTCh), el Fondo de Documentación de la Música Chilena y el Centro de Documentación de la Música Popular, todos pertenecientes a la Universidad de Chile; el Archivo de Música Popular Chilena de la Pontificia Universidad Católica de Chile (AMPUC), el Archivo de Literatura Oral y Tradiciones Populares (ALOTP) y el Archivo de Música de la Biblioteca Nacional. A esta última institución se donó en ceremonia del 14 de julio de 2016, el fondo documental Sello Alerce. Así quedó custodiada, conservada, pero también difundida y desarrollada, parte importante de la documentación de la historia cultural de la 
sociedad chilena desde el último cuarto del siglo XX. Entendiendo por música popular

una música mediatizada, masiva y moderna. Mediatizada en las relaciones entre la música y el público, a través de la industria cultural y la tecnología, pero también entre la música y el músico, quien adquiere una práctica musical a través de grabaciones, de las cuales aprende y recibe influencias. Es masiva, pues llega a millones de personas en forma simultánea, globalizando sensibilidades locales y creando alianzas suprasociales y supranacionales. Es moderna, por su relación simbiótica con la industria cultural, la tecnología, las comunicaciones y la sensibilidad urbana, desde donde se desarrolla su capacidad de expresar el presente, tiempo histórico fundamental para la audiencia juvenil que la sustenta y que al crecer, la atesora en la memoria (González y Rolle, 2005: 26).

La irrupción para el patrimonio nacional de este cuerpo documental implicaba desafíos y problemas que había que enfrentar en lo inmediato. La sociedad chilena, ahora sí, contaba con posiblemente el conjunto más sistematizado de vestigios que daban cuenta de aquellas tres cualidades que según la definición expuesta, constituyen la música popular -masividad, mediatización, modernidad-, por lo que era necesario desde ya activar su estudio. ¿Qué atributos contiene este fondo? ¿Se puede comprender en su historicidad? ¿Cómo puede un cuerpo documental vinculado a un sello de música popular, ser significativo para el estudio de la historia de Chile? ¿Qué nuevas posibilidades de comprensión, ofrecen las fuentes existentes en el fondo del sello Alerce? 0 más simple, ¿qué características nos ofrece un cuerpo documental emanado de la industria musical chilena? Son éstas algunas de las preguntas que motivan el ejercicio crítico que a continuación se presenta.

Un fondo documental emanado de la industria musical no tiene solamente la dimensión vital en cuanto sus componentes tienen una creación, una selección y una voluntad de custodia; también la tiene en cuanto su perfilamiento público forma parte de historias de vida. Los conjuntos de documentos -algunos más, otros menosposeen una dimensión vital inalienable en todos sus momentos. El Fondo Documental del sello Alerce tiene, en ese sentido, una historia que le otorga su especificidad y fortaleza. Esto por tres aspectos: la historia del sello como empresa vinculada a la figura y familia de Ricardo García; la producción documental de la empresa, compuesta principalmente de registros sonoros que fueron develados desde un proceso de investigación académico, y cuya diferencia con otros está marcada por su contexto histórico social y su propuesta política; y la historia descriptiva sobre la sistematización, restauración y resguardo patrimonial que 
permitió que la documentación del sello Alerce sea parte del Archivo de Música de la Biblioteca Nacional. Esta es la historia de un fondo documental, estructurada sobre aquellos tres aspectos.

\section{Alerce y Ricardo García}

La primera dimensión vital dice relación con que el sello fue creado desde la voluntad de Ricardo García y que, con el paso del tiempo, adquirió un cariz familiar donde las hijas, yernos y amigos terminaron conformando una industria atípica según los códigos mercantiles y empresariales, constituyendo cada documento o vestigio emanado parte de la propia historia del clan². No se puede obviar del sello Alerce su rasgo personalizado - no hablamos de aquel criterio de interés biográfico de los estudios musicales que desarrolla Sara Thornton (1990), quien define cuatro criterios mediante los cuales habitualmente se le otorga importancia histórica a un evento cultural mediatizado: nivel de consumo, nivel de mediatización, interés biográfico y aclamación crítica. Estas cuatro estrategias para ordenar el pasado: cuantificar, mediatizar, personalizar y canonizar, están en la base de toda investigación histórica sobre música popular que haya considerado como fuente las ventas, la media, el artista o el repertorio 'clásico' respectivamente" (González, 2001) - ni su entorno familiar. Esto no por hacer un panegírico, sino por entender a cabalidad los documentos.

Juan Osvaldo Larrea García, nombre oficial de Ricardo García, fue uno de los más importantes hombres de la industria musical chilena del siglo XX. Consagrándose desde 1959, luego de reemplazar como voz característica del primer programa-tocadiscos de la historia de Chile, "Discomanía", al fundador Raúl Matas, García fue protagonista de muchas de las experiencias sociales de la música popular que quedarían en la memoria colectiva. Fue el primer locutor del Festival de Viña del Mar, el año 1960; fue el primer animador del emblemático y fundacional programa de música televisada Música Libre, el año 1970; fue fundador del concepto Nueva Canción Chilena al ser organizador del primer festival del movimiento al amparo de la Pontificia Universidad Católica de Chile en 1969, y, lo que atañe especialmente a este trabajo, fue fundador el año 1976 del sello Alerce. Sobre su sentido, explicaba: “debía ser el rescate de una serie de valores dispersos. Restos de un movimiento -la Nueva Canción- ligado a mi propia vida" (García, 1996: 51-52).

No fue extraño por lo mismo, que el logo del sello estuviera formado por dos alerces, "árbol de madera dura, resistente a todos los climas, muy útil y generosa" (García, 1996: 51-52); uno talado y, en primer plano, el otro alto y fuerte. Era el

\footnotetext{
2 Bien da cuenta de aquello que, entre la documentación del fondo, parte importante no tiene que ver directamente con el sello, sino que con la vida profesional de Ricardo García previa a 1976, año de fundación de la empresa.
} 
símbolo de los restos de ese desarrollo cultural unipopular que la dictadura había intentado eliminar, pero que se proyectaba en otro similar que se erguía con igual ímpetu. Era la metáfora de la robusta resistencia de la música popular chilena de raíz folclórica con compromiso social.

Alerce editaría cientos de discos hasta el año 20103, acogiendo y perfilando tres de los movimientos más importantes en la historia de la música popular chilena: la Nueva Canción -en tiempos de exilio y dictadura-, el Canto Nuevo y el Nuevo Rock Chileno de mediados de la década de 1990.

Junto a Carlos Necochea, músico integrante de Los Curacas, García daba inicio a un sello con dos primeros grupos editados: Chamal y Ortiga. La música chilota y la fusión latinoamericana fueron los primeros sonidos. Del primero fue el primer disco del sello, con título elocuente de todo lo que hemos señalado: Tierra de alerces (1976). De fusión latinoamericana fue el segundo disco larga duración del sello, Ortiga, del grupo homónimo, verdadero testimonio de la resistencia de los códigos de la Nueva Canción en los tiempos más salvajes de la represión dictatorial.

Independientemente de que el sello proyectara dentro de sus posibilidades la música de una Nueva Canción Chilena que se encontraba perseguida, apresada, asesinada o exiliada, el primer movimiento musical perfilado en su origen desde la firma fue el Canto Nuevo, concepto que se consagró en 1977 cuando el selló editó un disco de larga duración titulado bajo el mismo nombre. El L.P. Canto Nuevo llevaba por carátula una paloma multicolor, símbolo de la libertad y la esperanza ${ }^{4}$, y fue la irrupción histórica del término, el bautizo del movimiento. El nombre se repetiría para cuatro compilados más y algunas antologías posteriores, todas recuperando y presentando el mismo símbolo. Fue, al fin, la consolidación histórica de la tendencia musical cuyas raíces se podían remontar a la música tradicional folclórica, a la música popular masiva, a la Nueva Trova cubana, al jazz y a la música docta.

Después de más de una década trabajando en difíciles condiciones, con represión y censura a la orden del día, había esperanzas en que, con el retorno a la democracia, las cosas cambiarían para bien. Empero, el inicio de la última década del siglo XX, a pesar de lo que se pensaba, fue amargo. Si bien se había acabado la dictadura política cívico-militar y se iniciaba una transición hacia la democracia, los significativos continuismos de la obra pinochetista se hacían evidentes en

\footnotetext{
3 El sello Alerce sigue en pleno funcionamiento.

${ }^{4}$ La paloma fue un símbolo sumamente presente durante la dictadura. Además de los discos del sello Alerce que llevaron su figura en la carátula, el muralismo resucitado desde la década de 1980 también la incorporó como motivo recurrente en sus composiciones estéticas. Gran parte de los murales realizados en poblaciones como La Victoria o Villa Francia, tenían a la paloma entre los motivos más llamativos. A su vez, era objeto recurrente en piezas artesanales que se comerciaban en calles, ferias y mercados informales de todo Chile. Sería interesante realizar un catastro sobre cuantas niñas que nacieron entre los años 1973 y 1989 fueron bautizadas con el nombre Paloma. Es probable que fueran miles.
} 
dificultades que el sello debía enfrentar. La apertura económica implicó una competencia desigual para con las transnacionales que encontraban en este humilde país un interesante mercado, y la esperanza en el acceso a la masificación -negada hasta entonces por el régimen militar- terminó siendo una quimera. El mayor ejemplo de aquello, especie de metáfora de los tiempos finiseculares, fue cuando el sello y el propio Ricardo García vieron cómo eran invisibilizados mientras Silvio Rodríguez se presentaba ante una multitud en el Estadio Nacional en marzo de 1990.

Efectivamente, Alerce fue en gran parte el responsable de la escucha social de la Nueva Trova cubana en Chile durante las décadas de 1970 y 1980. La cercanía de García con el Partido Comunista de Chile y el gobierno cubano, además de la amistad con Silvio Rodríguez, permitió que este tuviera un contrato de distribución con el sello, lo que derivó en que todos los registros - casetes por ese entonces- editados en Chile del cantautor cubano, fueran del sello Alerce. Tras él, todos los artistas del movimiento musical caribeño fueron entrando a un pequeño y a veces subterráneo mercado, donde la cinta pirata era parte constitutiva de la experiencia social de la música. La omisión de García y su sello en la primera visita de Silvio a Chile luego del fin de la dictadura, fue un golpe duro de absorber.

La frustración fue mayor. A pesar de las gestiones que personalmente realizó el disc-jockey en Cuba para conseguir la gira a Chile de la estrella isleña, los esfuerzos fueron vanos. El magno recital fue organizado por la productora Providencia Televisión a través de Fernando Meza y Luis Venegas, luego de negociaciones con el representante Tito Márquez y el jefe de prensa Pedro de la Hoz. Fue esa misma agencia la que aprovecharía la ocasión para publicitarse y generar subproductos. "Dos volúmenes con una selección de 80 canciones considera el libro 'Silvio Rodríguez en Chile. La obra completa'. (Es una recopilación de temas entre 1966 y 1989, con arreglos para guitarra). La publicación es responsabilidad de Ediciones la Cigarra y Providencia Televisión", informaba la prensa de la época5. Y de Alerce, nada. El sello que se había atrevido a editar música que era considerada por el régimen de Pinochet como subversiva y por lo mismo reprimida, y había tenido el coraje político de sugerir la resistencia y oposición desde la música en álgidos tiempos, tenía la ocasión para atender el reconocimiento del pueblo chileno, y nada. Es más, al poco tiempo Silvio Rodríguez abandonaría la casa disquera ${ }^{\text {. }}$

El evento fue simbólico para un cambio de tiempo: retornaba la democracia, abandonaba el sello uno de sus artistas consulares, y moría su fundador, Ricardo García, un 2 de junio de 1990. Se concluyó así un ciclo y se inició uno nuevo con la dirección asumida por Viviana Larrea, su hija, debiendo ahora enfrentar nuevos desafíos. Por una parte, el mercado brutal se hacía patente con la arremetida de Emi,

5 La Época, 29 de marzo de 1990, s/p.

${ }_{6}$ En círculos íntimos y familiares se suele comentar que una de las causas de la muerte de Ricardo García, el 2 de junio de 1990, fue el dolor causado por esta situación. 
Warner y oras transnacionales que obligaba a generar estrategias de alianzas corporativas para aunar esfuerzos. Por otra, los soportes analógicos perdían terreno y obligaban a la edición digital, situación en la que Alerce publicó su primer disco compacto en enero de 1990: Para mis amigos, del pianista Roberto Bravo.

En este marco irrumpió el Nuevo Rock Chileno, movimiento que se fraguó hacia mediados de la década de 1990, en plena transición hacia la democracia. La escena musical chilena había cambiado: la censura se había atenuado hasta casi extinguirse, la represión se estaba transformando en un mal recuerdo (...), la canción social (Díaz, 2007) nuevamente se presentaba desde escenarios públicos y mediáticos, y el rock había revivido desde la década de 1980 para no extinguirse. En ese marco el sello, luego de una estratégica alianza con la transnacional Sony Music 7 -obteniendo la primera recursos que no tenía y la segunda la participación de artistas de gran proyección-, presentó en un gran recital en el Estadio Nacional a ocho bandas que bajo el rótulo antes mencionado, irrumpían en la escena musical desde la marginalidad urbana, con un mensaje social y una irreverencia reflejada en el hardcore, el rap, el funk o el rock: Chancho en Piedra, La Floripondio, Mal Corazón, Santiago Ludwig Band, Los Morton, Panteras Negras, Los Miserables y Pozze Latina, fueron los referentes del Nuevo Rock Chileno.

A través de estos tres movimientos, Alerce daba continuidad a la historia musical de la sociedad chilena durante casi cuarenta años. Sus registros sonoros, material gráfico, recortes de prensa o informativos, se transformaban en potenciales vestigios para ser interrogados por las ciencias sociales en su intento permanente por saber quiénes somos a través de comprender quiénes fuimos, es decir, a través de la historia. ¿Qué fue de esos documentos? ¿Qué es de estos documentos?

\section{El sello Alerce y su historia en dictadura}

Parte importante de los 17 años de dictadura pinochetista tuvo en la invisibilización de la cultura anterior una característica capital (Donoso, 2019). La censura y represión eliminaron algunas experiencias sociales y culturales, mitigaron otras y muchas las prohibieron bajo el garrote de la represión. Ello implicó que se perdieron, o no existieron, muchos vestigios; muchos de sus años son difíciles de comprender desde la historia por no plasmarse en indicios accesibles, cotidianos, oficiales, efectivos; en fin, fuentes. En medio de una historia en estado mudo, que se expresaba desde lo oficial, lo permitido, sólo de modo parcial y hasta a veces desde una mordaza, en medio de ello, las fuentes convencionales no hablaban de lo real a plenitud. No daban cuenta de pobreza, violación sistemática de derechos humanos, censura, coerción u omisión.

\footnotetext{
7 Alerce Informa, noviembre de 1995, p. 2.
} 
Corría el año 1981, febrero, verano. En Chile hacía pocos meses se había aprobado en un plebiscito sin ninguna garantía de legitimidad, una nueva constitución que reemplazaría a aquella que regía los destinos jurídicos de la nación desde el año 1925. Si bien la dictadura de Pinochet había atenuado su coerción desde un salvajismo vergonzoso hasta una represión controlada, los estados de excepción seguían formando parte de una vida cotidiana donde una generación entera había sido afectada por el Golpe de Estado del 11 de septiembre de 1973, y una siguiente no conocía otra vida que no fuera la permanencia en censura, actos cívicos, control policial, rumores de asesinato y tortura, temor y latente rebelión.

Febrero era el año del Festival de la Canción de Viña del Mar, emblemático evento de música popular masiva en Chile. En aquella versión de 1981 se presentó en la competencia folclórica la canción "Linda la minga"8, composición de Richard Rojas interpretada por el conjunto Santiago del Nuevo Extremo que obtendría el segundo lugar. Era una de contadas ocasiones en que una canción popular de raíz folclórica asomaba desde un medio de comunicación masiva ${ }^{9}$. La canción aparecería algunos meses después como el tercer tema del lado B en la primera publicación del grupo, en formato casete, editado por el sello Alerce.

Se juntaron, entonces, dos fenómenos. Por un lado, una industria cultural que desde la audiovisualidad y la producción en masa generaba la atmósfera sonora de una época. Segundo, un movimiento cultural de música popular de raíz folclórica que provocaba desde los sonidos, sobre la base de la contingencia, la denuncia y la protesta. Este, como veíamos, conocido como Canto Nuevo y que se acreditaba como digno sucesor de la emblemática Nueva Canción Chilena, tenía en Richard Rojas y Santiago del Nuevo Extremo dos dignos exponentes. Ambos fenómenos se sintetizarían desde un emblemático sello que acogería muchas de aquellas expresiones que el modelo dictatorial imperante, por decir lo menos, omitía.

Pues bien, entre ambos fenómenos, dando cuenta de ambos atributos, irrumpía Santiago del Nuevo Extremo, que sí se podía leer, contemplar y escuchar desde su casete $A$ mi ciudad, el primero del grupo y donde aparecía aquella canción

\footnotetext{
\& Santiago del Nuevo Extremo. "Linda la minga". Por Santiago del Nuevo Extremo. A mi ciudad. Alerce, 1981. Casete.

9 En vista de las condiciones que ofrecía el modelo económico implementado desde 1974 en Chile, la industria musical nacional sufrió una merma importante que impidió a los artistas chilenos grabar para tener presencia en las radios y, en general, en el mercado. Ello implicó que la televisión, a través de los festivales y programas de concursos principalmente, se transformara en uno de los medios más importantes de desarrollo musical. Producto del control autoritario de la dictadura, pocas expresiones de canto con contenido social fueron emitidas desde el sistema de comunicación de masas. Sin embargo, desde la televisión se pudo escuchar en el Festival de Viña de 1978 a Mariela González cantando en la competencia internacional "Un motivo para cantar", de propia autoría; a Santiago del Nuevo Extremo con el tema antes mencionado y con "El trauco" el año siguiente; o al grupo Abril, intérpretes de "La semilla" de Patricio Valdivia, en 1982.
} 
concursante en el Festival de Viña. El mismo tema que le daba el nombre al disco10 era una excelente postal de la capital chilena de aquel entonces, y de la necesidad de denunciar el agobio del militarismo ("en mi ciudad murió un día el sol de primavera, a mi ventana me fueron a avisar"). Era un vestigio de la dictadura, una fuente.

El tiempo, reconocido por Tomás Moulian como la "fase terrorista" de la dictadura (Moulian, 2002) y caracterizado por Luis Errázuriz (2012) como "de corte y limpieza", fue cubierto para los investigadores de la sociedad con una bruma. "La penumbra de mi ciudad no es paso bajo de la bruma/es manto negro que cubre las verdades desnudas"11 cantaba el grupo Abril, uno de los referentes del Canto Nuevo. Buscar fuentes que nos hablaran de sus actores, procesos y tendencias era una verdadera aventura, pero había algunas pistas, la música una de las importantes, de las cercanas: como objeto y como instrumento de lectura; como medio y como mensaje. "A mi ciudad" y "La penumbra" hablaban de aquello.

Parte de la heurística natural al ejercicio musicológico histórico es el encuentro con la fuente. ¿Dónde encontrar? Es el problema de muchos investigadores para comprender tiempos invisibilizados como, por ejemplo, gran parte de la dictadura militar de Pinochet.

Todo cuerpo documental tiene una dimensión vital, más sutil, menos evidente. Dice relación con su encuentro, recuperación, conservación y aprovechamiento, asunto que tiene directa relación, en primer lugar, con el encuentro entre el investigador y sus fuentes, y, segundo lugar, con la voluntad consensuada de rescate de las mismas, aunándose voluntades de personas naturales y jurídicas con el objetivo de incrementar el patrimonio documental chileno y, sobre esa base, con que nuestro país tenga más y mejor historia.

Sergio Araya es un investigador con formación de pregrado entre los años 1987 y 1994, en Licenciatura en Historia del Arte en la Universidad de Chile. "A mi ciudad" fue parte de la banda sonora de aquella vida universitaria junto a "Homenaje"12 del mismo conjunto -en honor de Víctor Jara- o "Tic tac"13, tema instrumental del grupo Ortiga que sonaba como cortina musical de uno de los más emblemáticos programas radiales de las décadas de 1970 y 1980: "Nuestro canto", conducido por Miguel Davagnino en radio Chilena todos los domingos desde las 22 hrs. Araya contaba:

Yo tenía originales del sello, que se prestaban para su copia. Era muy significativo: hasta hoy tengo la colección del sello Alerce. Así de

\footnotetext{
10 Santiago del Nuevo Extremo. "A mi ciudad". Por Santiago del Nuevo Extremo. A mi ciudad. Alerce, 1981. Casete.

11 Abril. "La penumbra de mi ciudad". Por Grupo Abril. Grupo Abril. Alerce, 1982. Casete.

12 Santiago del Nuevo Extremo. "Homenaje". Por Santiago del Nuevo Extremo. A mi ciudad. Alerce, 1981. Casete.

13 Ortiga. "Tic Tac". Por Ortiga. Ortiga. Alerce, 1976. L.P.
} 
importante. Eso, junto a la revista La Bicicleta, crecí en esta área. Junto al café del Cerro. La trilogía era: casetes Alerce, La Bicicleta y el Café del Cerro14.

El investigador mencionado empezó a cursar el Magíster en Musicología el año 2013, instancia en que el tema de tesis terminó definiéndose como "Industria discográfica en Chile 1973-1989", problemática surgida desde el enfrentamiento al concepto establecido, controvertido y equívoco, de "apagón cultural". Ello, pues desarrollo musical existió y ha existido siempre, pero de modo subterráneo, marginal, solapado, producto del control coercitivo, del corte y limpieza. Pues, apagón cultural no hubo; sí, merma en la industria cultural chilena. Producciones de todas las artes se vieron inhibidas por causas estructurales -refundación económica y política- que dieron una apariencia de vacío, pero "la verdad es que música había, y mucha” (Araya, 2016). Mas, ¿cómo se escuchaba si la producción había mermado tanto?

Efectivamente, el período comprendido entre 1973 y 1984, tuvo sus bemoles en cuanto a la industria musical. En 1972 se producían 6,3 millones de discos; ocho años después sólo se produjeron 968 mil, siendo la participación de música chilena en el mercado de menos del 30\%. A continuación, un cuadro que da cuenta de porcentajes de música radiodifundida y música adquirida en el mercado, construido con estimaciones solicitadas a entrevistados vinculados a la industria fonográfica (Fuenzalida, 1985: 18), del año 1985:

\begin{tabular}{|l|c|c|}
\hline Género musical & $\begin{array}{l}\text { Porcentaje promedio } \\
\text { de ejecución radial }\end{array}$ & $\begin{array}{l}\text { Porcentaje } \\
\text { promedio } \\
\text { ventas }\end{array}$ \\
\hline Internacional & 90 & 60 \\
\hline Nacional & 1 & 2 \\
\hline Música clásica & 2 & 1 \\
\hline Música ligera & 3 & 7 \\
\hline Canto Nuevo & 0,5 & 5 \\
\hline Rock chileno & 0,5 & 3 \\
\hline Folklórica chilena & 1 & 2 \\
\hline Popular masiva & 2 & 20 \\
\hline & $100 \%$ & $100 \%$ \\
\hline
\end{tabular}

Es evidente que las cifras de música chilena estaban en desmedro frente a la extranjera ("internacional", según el cuadro), no dejando de llamar la atención que

\footnotetext{
14 Conversación con Sergio Araya, Biblioteca Nacional, 3 de enero de 2017.
} 
dentro de la nacional se especifiquen tres géneros: rock chileno, folclórica chilena y Canto Nuevo. Hubo un sello y un soporte que se identificaba con los tres por ese entonces: Alerce y el casete.

Había una experiencia personal de historia social de la música para el período objeto de análisis, que era la audición desde el casete re-grabado, informal, "pirata". Era parte de un proceso de copiado infinito que bien podía escudriñarse en la versión original, la que probablemente era una casete del sello Alerce. Un procedimiento sensible y doméstico, como era la audición musical, se transformaba en otro subversivo, alternativo y subterráneo. Era otra música en todos los aspectos sociales que la experiencia sonora implicaba: en creación, grabación, distribución, adquisición y audición. Era la experiencia social de la música, pero también era el indicio de su época. Había, entonces, que ir al sello de la otra música: Alerce.

La investigación musicológica de Araya condujo, pues, a los actores que pudieran dar testimonio del sello. Qué mejor que sus actuales ejecutivas quienes, además, eran las hijas del fundador. Viviana y Mónica Larrea habían asumido, sobre todo la primera, la dirección de Alerce desde comienzos de la década de 1990. La recuperación de su testimonio era fundamental para la reconstrucción de su tiempo. Era menester el trabajo hacia la memoria, era necesaria la construcción de la fuente oral (Araya, 2016)15.

Elocuente fue la disposición absoluta de ambas para hablar sobre Alerce, en el sentido que había consciencia de que la relevancia del sello para la historia debía conocerse y había que trabajar en aquello. La complicidad e interés mutuo entre el investigador y su fuente, permitió la irrupción de un tesoro. Irrumpió la información: "La Vivi tiene $\mathrm{N}$ material y lo tiene en la casa, en un container"16. Es menester advertir que hubo una intención de resguardo no sólo por las necesidades de una empresa, sino en parte importante por la dimensión afectiva del material. La documentación rescatada era Alerce, pero también era un padre; era una empresa, pero también una familia. Elocuente era, en este sentido, que se hubiera custodiado en el hogar de Viviana Larrea.

La información se transmitió a la brevedad a la institución pertinente. Araya estaba realizando una pasantía en el Archivo de Música de la Biblioteca Nacional, que había nacido oficialmente el 18 de diciembre de 1970, pero que se consolidó luego de la reformulación de la sección Música y Medios Múltiples, recién durante el siglo XXI. Era, por cierto, la instancia encargada de hacerse cargo de aquel legado que generosamente se estaba poniendo a disposición de la sociedad chilena.

El contacto entre la directora del archivo, Cecilia Astudillo, y las hermanas Larrea fue presto, fluido y fructífero. La conclusión era un consenso evidente: había

15 Las susodichas fueron entrevistadas para la realización de la tesis de Araya, y además en el marco del proyecto de investigación que da a luz este artículo.

16 Mónica Larrea. Entrevista realizada en 7 de diciembre de 2016. 
que rescatar todos los documentos para el Archivo pues era el patrimonio musical chileno de los últimos 35 años. Grata fue la sorpresa para la familia Larrea, que una institución tan consolidada como la Biblioteca Nacional, a través del Archivo de Música, se preocupara de aquello. La urgencia de la situación implicó que la operación de reconocimiento, primero, y luego traslado para su restauración y conservación, fuera realizada a la brevedad.

La primera inspección ocular fue inmediata y el diagnóstico inicial fue adverso. Se vieron cajas, góndolas con cintas reel y VHS, con una estimación a priori de un $20 \%$ de material estropeado, insalvable, todo en medio de un somier, bicicletas, esquís y cachureos varios. Había cierta sistematización del material acopiado, pero las condiciones de almacenamiento hacían imperativa la acción de rescate, pues el peligro de pérdida total era inminente.

Se decidió el siguiente paso: hacer el conducto regular sobre la base de un manual de procedimientos de las donaciones. Paso uno, establecer contacto con el posible donante y establecer grados de confianza. Luego, la inspección de la documentación, también efectuada. A continuación, paso tres, se redactó y presentó un informe al Comité Receptor. Éste era un consejo resolutivo compuesto por la entonces directora de la Biblioteca Nacional Ana Tironi, y el Grupo de Archivo de Música GAMUS, comité a su vez conformado por Gabriel Matthey como representante de la Asociación Nacional de Compositores ANC; Marisol García, desde el sitio de música www.musicapopular.cl; Jorge Mahud, de la Sociedad Chilena del Derecho de Autor SCD, y Germán Torres, del área patrimonio de los sellos independientes. La aprobación no se hizo esperar

Así, el 6 de noviembre de 2015 empezó el traslado en vehículo oficial de la institución, del material desde la casa de Viviana Larrea, ubicada en el sector Lo Cañas, hasta las dependencias del Archivo de Música en la Biblioteca Nacional, en el centro de Santiago. Se definió la necesidad de asistencia de un musicólogo, un conservador y el jefe del archivo, independiente de colaboradores, todos bienvenidos. Fue así como participaron de la tarea: Cecilia Astudillo, directora del Archivo de Música; Sergio Araya, musicólogo, descubridor del hallazgo, y Javiera Rodríguez, conservadora. Además de ellos: Jorge Canales, musicólogo; Marusela Ramírez, investigadora y encargada del registro fotográfico, y Claudio Camilo, funcionario del archivo. El equipo, sobre todo Araya y Astudillo, se encontraba con piezas que reconocían desde casi siempre. El máster del disco "La alegría ya viene", himno de la campaña por el No para el plebiscito de 1988, algún máster del conjunto Congreso, las maquetas para la carátula de algunos discos de Santiago del Nuevo Extremo, casetes de Schwenke y Nilo, Patricio Manns y Patricio Liberona, eran sólo ejemplos de miles de documentos cuya relevancia era evidente, en un ambiente lleno de hongos y polvo. Parecía el descubrimiento de un tesoro en el fondo del mar. 
Se realizaron dos viajes de mudanza desde la casa, más uno desde la oficina de Alerce donde también se había acumulado una cantidad importante de material, de tal modo que en enero de 2016 toda la documentación se encontraba apilada en cajas que debían ser examinadas y sometidas a cuarentena para establecer lo que debía ser eliminado - pues por estado podía contaminar el resto- y lo que finalmente iría a depósito. Dos tercios del material original tuvieron que ser desechados, sometiéndose el porcentaje restante a estabilización para su posterior trabajo de catalogación y restauración.

Todo el proceso fue emotivo. Viviana estuvo siempre presente, al igual que otros miembros de la empresa o de la familia. Eran sentimientos encontrados; se sabía que iban a estar mejor resguardados todos aquellos vestigios del pasado, pero era también desprenderse de algo muy íntimo, algo así como las cenizas del padre.

Pero su transcendencia no era sólo íntima o familiar. Era un conjunto de vestigios que se constituían desde lo musical, pero cuya capacidad de dar cuenta de la dimensión temporal de la sociedad iba más allá que lo sonoro. Este ámbito, en cuanto texto, ciertamente que daba cuenta de un tiempo pasado; la lírica de algunos movimientos como el Canto Nuevo o el Nuevo Rock Chileno era protesta, crónica, denuncia y relato íntimo, así como los sonidos hablaban de sensibilidad subcontinental latinoamericana o memoria a través de la cita del sampler.

Pero no sólo el texto; el soporte era también fuente para la historia. Cintas reel, discos de vinilo, casetes, además del arte de carátula, bosquejos, diseños y textos introductorios, daban cuenta no solamente de una obra musical, sino de actitudes, mentalidades y valores de más de veinte años de historia reciente de Chile. La bomba molotov en la portada del casete Te mataré con amor de Los Miserables, era tan elocuente para dar cuenta del año 1995 como lo que cantaba Santiago del Nuevo Extremo sobre Santiago para 1981; la celda que encarcelaba a los Panteras Negras en su casete Reyes de la Jungla (Alerce, 1995), hablaba tanto de su año como los sonidos de La Gran Noche del Folklore para el año 1983.

Una tercera dimensión testimonial de estos vestigios para la historia era su experiencia social, su audición. Advertida principalmente desde recortes de prensa y boletines corporativos (y sutilmente desde documentos contables, administrativos y comerciales), la dimensión del público también estaba contenida desde las fuentes que ahora se instalaban en un espacio público para su resguardo, conservación y disposición. Texto, soporte y audición se evidenciaban como factores asibles para el ejercicio crítico desde la investigación, en el momento de trabajar los documentos generados por un sello musical para comprender la historia reciente de la sociedad chilena. 


\section{El tratamiento del documento musical desde el archivo ${ }^{17}$}

La base de un archivo son los conjuntos de documentos: los Fondos Documentales. Tienen siempre un único productor: los documentos representan lo que éste ha realizado en el ejercicio de sus funciones. Todo vale si es producido por esta entidad o persona en el ejercicio de sus funciones.

Entendiendo como fondo documental un conjunto de documentos independiente del soporte o tipo de éstos- producidos orgánicamente y acumulados por una persona física, familia o entidad en el transcurso de sus actividades y funciones como productor, la archivística también reconoce para aquél una dimensión diacrónica, una vida desde un aspecto técnico. En este sentido se identifican tres edades de un archivo (Astudillo, 2016; Cruz Mundet, 2003; Gómez González, 2018).

La primera edad se reconoce como Archivo de Gestión y corresponde a los momentos de vida útil del documento. Esta estimación es de unos cinco años, correspondiente al tiempo de los documentos en su fase de tramitación y con uso frecuente para la gestión. Es el tiempo cuando la documentación está bajo la responsabilidad directa de las unidades administrativas. En el caso específico del sello Alerce, dentro de este tiempo cabría toda la información contable, legal y comercial, pero hay que advertir una especificidad. Cuando el productor es una industria discográfica, como es el caso, no sólo se genera ese documento convencional. También forma parte de esta vida la generación de documentos sonoros y gráficos que se transforman en insumos del producto final, y que también tienen una vida útil. Es así como masters, maquetas, bocetos, diseños y pruebas de sonido constituyen también parte de la documentación perteneciente a esta edad.

La segunda edad corresponde al Archivo Intermedio. En esta instancia se guardan los documentos que no se usan en la inmediatez, pero que pueden ser consultados dependiendo de las circunstancias y necesidades del productor, pues aún no pierden completa vigencia. Dejan de ser utilizados con frecuencia, pero asumen la cualidad de medio probatorio, siendo posible el hecho de que un recurso o problema sobre un asunto determinado, los haga regresar a la edad anterior. Por lo mismo, no se eliminan. En esta etapa se hace un expurgo: se elimina información y se guarda lo que se piensa que en algún momento se puede utilizar. Es un proceso natural, un darwinismo documental.

La tercera edad constituye el Archivo Histórico, la conformación definitiva del fondo documental; luego de una expurgación natural, se guarda lo que se considera

\footnotetext{
17 En el desarrollo de este acápite fueron de particular utilidad los informes realizados por Nicolás Salas, Pablo Maldonado, Nicolás Galindo y Javiera Vergara, todos pasantes y/o practicantes en el Archivo de Música al momento de desarrollarse la investigación que generó este artículo, y quienes realizaron todas las labores descritas en esta parte del texto.
} 
tiene un valor para la historia. Es el momento en que se realiza la selección por su valor informativo, histórico y cultural. Es el momento en que irrumpe el valor de la conservación a perpetuidad, en condiciones que garanticen su integridad y transmisión a generaciones futuras. Mas, como todo ente en tercera edad, puede quedar a la deriva, en manos del destino, a su propia suerte.

Alerce no era un organismo productor cualquiera (bueno, ninguno lo es). Era una empresa construida con un sentido político que la hizo particularmente significativa en su primer tiempo y espacio (1976-1990); era obra de uno de los personajes más importantes en la historia de la música popular chilena, y en ella el modo de operar cercano, cómplice y comprometido le agregó un cariz familiar que pocas industrias musicales poseían. Fue esa la característica que implicó que la primera edad del archivo se conformara sobre los materiales funcionales a la empresa, los que, como decíamos, no consistían sólo en documentación escrita convencional sino también, y por sobre todo, en material sonoro consistente en cintas reel y dat -sostenes de los fonogramas editados a lo largo de las tres décadas de gestión- y material gráfico que abarcaba desde bocetos, dibujos, maquetas y pruebas de imagen, hasta carátulas, portadas y afiches en sus versiones finales.

No sólo eso. El productor editó también el informativo corporativo Alerce informa, donde se daba cuenta de las actividades del sello en cuanto a lanzamientos, recitales, festivales, giras o conferencias de prensa18; y se preocupó de ir recolectando in situ toda la información aparecida en la prensa escrita vinculada al sello $^{19}$. Fue así como se fue componiendo un corpus documental que parecía ser su funcionalidad inmediata, la proyección hacia el futuro. En el caso del fondo presente, la primera edad del archivo se ligaba desde su generación, a la segunda; la función práctica de este último tipo de documentación no era otra que dar cuenta de su desarrollo. Fue, pues, un fondo documental conformado con conciencia histórica. No sería extraño, por lo mismo, su donación al patrimonio nacional.

La segunda edad del archivo para el sello Alerce, pues, tiene también una distinción frente a otras empresas productoras: su conciencia de la relevancia de su acontecer para su tiempo y espacio. Más allá de la necesidad administrativa y posibilidad de utilidad práctica del documento (administrativo, sonoro o gráfico), Alerce hizo partícipe de esta etapa a todo ese material de prensa cuyo único sentido era acreditar presencia. De alguna forma, el sello tuvo conciencia de la necesidad de

\footnotetext{
18 Alerce informa. Alerce: Santiago, 1995-2000.

19 El Tiempo, 21 de marzo de 1977, s/p. "Se Inicia Serie de Recitales Folklóricos. El sello Alerce anuncia una serie de recitales folklóricos. El primero de ellos se efectuará el viernes 25 en el salón auditorio Don Bosco (...)". Las Últimas Noticias, 9 de marzo de 1978, s/p. "Regresó García. Luego de un mes y medio de visitar diversos centros artísticos europeos regresó Ricardo García, director de sello Alerce. Este es su boletín noticioso (...)". Son dos ejemplos de documentación resultado de la labor apuntada.
} 
generar vestigios para los historiadores del futuro. Y esa sensibilidad histórica no se plasmó sólo en esa acción; parte significativa de los recortes de prensa y fotografías conservadas, fueron previas al año 1976.

Efectivamente, parte importante de la documentación de la segunda vida del archivo, es previa al tiempo del productor. ¿Cómo se explica? Por la especificidad histórica que asumió la empresa, y la identidad familiar y política de la misma. Toda la documentación aludida tiene que ver con la vida de su fundador, Ricardo García.

Sobre la tercera edad, en vista de los atributos de la documentación advertida, el proceso de ordenamiento y catalogación se estructuró desde un cuadro de clasificación ordenado en tres secciones: documentos sonoros y audiovisuales, documentos administrativos y sección gráfica.

Para la primera sección de documentos se identificaron dos series, entendidas técnicamente como conjuntos de documentos organizados, homogéneos en su tipo documental (Astudillo, 2016). La primera se identificó como Máster e incluía aquellos cuyo mensaje era efectivamente sonoro. Por lo mismo, sus subseries fueron: C.R. (cintas reel), VHS, CASETES, B.CAM y DAT. La segunda, sin embargo, merece una observación que alumbra sobre el fondo en particular. Esta segunda serie de identificó como Notas de Prensa y Spot, identificándose sus subseries de la misma forma que la serie anterior. La observación se refiere a que, técnicamente, la archivística se ve de alguna forma con una camisa de fuerza disciplinaria al deber atenerse a la homogeneidad del tipo documental para dar cuenta de categorías y cualidades de documentos diferentes, para el caso específico de la experiencia musical. Efectivamente, masters, prensa y spot pueden dar cuenta de sonido e imagen, pero el sentido y la lectura a la que apelan es distinto. Obliga, en este caso, al investigador a diferenciar el estímulo, ergo el contenido, pero descubriéndolo desde el encuentro con el documento y no desde su catalogación.

La siguiente sección es aquella propia de toda empresa: documentos administrativos. Se le otorgó una serie, Contables, con subseries: Exportaciones, Facturas emitidas, Facturas recibidas y Boletas. Pocas veces el investigador de cultura, y específicamente de música, puede realizar un análisis cliométrico de la experiencia musical desde el documento cuyo contenido es cuantitativo. La posibilidad, por lo tanto, que ofrece esta sección es notable y debería motivar el desarrollo de una perspectiva metodológica afín a ese objeto.

La dimensión gráfica constituye la última sección construida en este fondo, destacándose por su contundencia y calidad de conservación. En ésta se incorpora una categoría que amerita y que bien alumbra sobre la calidad de la documentación resguardada: la de Documento Compuesto o Expediente. Ésta se refiere al conjunto de documentos referidos a un mismo tema, actividad o asunto, reunida desde la incorporación sucesiva de éstos en la edad primera del archivo. No importa en esta categoría el tipo de documento, el soporte en que se sostenga, el sentido al que apele 
ni el tipo de lectura que ofrezca. Todos juntos constituyen el sentido. Por lo mismo, la extracción de cualquiera de ellos conduce irremediablemente a su pérdida.

El cuadro de catalogación de esta última sección quedó conformado por tres series: afiches, fotos y carátulas. Para cada una de ellas se definieron las siguientes subseries: documentos, para la serie afiches; negativos, diapositivas, fotos, "Ricardo García” y "20 años", para la serie fotos; dvd, casetes y cd's para la serie carátulas. Cada una de las series y subseries incluye expedientes junto a los documentos, películas, masters, fotos y disquetes.

Por un requerimiento pragmático y en vista de las posibilidades ofrecidas por el cuerpo profesional del Archivo de Música, la labor de catalogación, restauración y conservación fue transversal a las secciones recién descritas y se parceló en tres áreas: sonora, gráfica y prensa.

Respecto a los documentos sonoros, se revisaron cintas reel de distintos tamaños, principalmente de 10 pulgadas, advirtiéndose un estado de conservación entre regular y malo. Su contenido correspondía a variadas grabaciones de estudio que luego serían comercializadas en formato casete, y conciertos en vivo de música chilena entre los años 1960 y 1980 aproximadamente.

Respecto a las cintas reel, siendo su estado de conservación aceptable, el estado de sus contenedores variaba entre regular, malo y muy malo. Las cajas originales presentaban deficiencias como: rasgones, manchas, erosiones, adhesivos, corchetes, deformación del plano, humedad, faltantes, ataque de xilófagos y hongos. Todo esto hacía imperativo el cambio de embalaje, labor que se realizó durante un período de tres meses para lo cual se elaboraron 150 nuevos contenedores, confeccionados con cartón forrado libre de ácido, de 210 grs.

Debido a que la manipulación de hongos es altamente riesgosa para la salud -poseen esporas de tamaños invisibles, que pueden llegar a cualquier lugar del cuerpo humano y alojarse ahí (piel, uñas, ojos, pulmones, etc.)-, se contó con la asesoría de un biólogo y un ingeniero en prevención de riesgos, quienes recomendaron la utilización de buzos de tyvek, guantes de nitrilo, lentes protectores y máscaras con filtro. Se estableció así un procedimiento para realizar el cambio de embalaje, procurando mantener la higiene y seguridad de quienes manipulaban el material contaminado. El procedimiento se llevó a cabo en un lugar abierto y ventilado, delimitando un área sucia y un área limpiazo .

20 El procedimiento paso a paso fue el siguiente:

10: Instalación de la caja contaminada sobre la mesa de área sucia.

2o: Registro fotográfico de la caja cerrada.

3: Registro fotográfico de la caja abierta.

40: Registro de cualquier información relevante.

50: Registro en detalle del estado de la cinta reel, si su estado de conservación lo ameritaba.

60: Traslado de la cinta reel al nuevo contenedor.

7ㅇ: Desecho de la caja antigua. 
A continuación se elaboró un inventario en plantilla Excel, con información relevante sobre el contenido, ordenada según los siguientes campos: número, sección, soporte, formato (tipo), título, “tiene caja?”, sys, observación, inspector, fecha, ubicación. En esta primera etapa se llenaron los campos más relevantes: número, sección, soporte, título, “tiene caja?”, inspector y fecha.

Respecto al área gráfica, el primer paso fue revisar las cajas que contenían el material gráfico donado por el sello. En total eran dos, las que en su interior tenían todo tipo de materiales sueltos o guardados en expedientes con los nombres de los músicos a quienes correspondían. También se encontró gráfica asociada al sello en la producción y/o difusión de algún evento musical en particular. Los tipos de material encontrado fueron: carátulas (de discos y casetes), masters de carátulas (en formato de películas/transparencias y/o maquetas/diseño), diapositivas, fotos, películas/transparencias, negativos fotográficos, textos, afiches y volantes.

En general los materiales gráficos como las fotos, las diapositivas, los covers, los afiches y los volantes, se hallaron en un estado de conservación entre regular y bueno. Por el contrario, los elementos más perjudicados por los factores de tiempo y de condiciones de conservación fueron las películas/transparencias y algunos masters de afiches. En ellos se advirtió brote de hongos y roturas. También se hallaron algunas hojas de textos unidas con corchetes (como, por ejemplo, fichas técnicas de conciertos) que acumularon óxido en las partes de metal. Por último, todas las carátulas de CD se hallaron en buen estado, no tanto así las de casete, específicamente las que estaban adheridas a los sobres de los masters de carátula y a las cajas de las cintas reel.

El total del material encontrado se pudo agrupar en tres categorías: carátulas (de casete o CD), expedientes y el material gráfico suelto, este último asociado a cada uno de los anteriores.

Para la elaboración del inventario (ordenado y guardado en planilla Excel), se hizo una lista según el sistema de codificación y enumeración del mismo sello, catastrándose todas las carátulas de casetes y discos halladas en las cajas de la sección gráfica, los expedientes de carátulas, las adheridas a las cajas de las cintas reel y las archivadas en el libro de carátulas de discos. Asimismo, para obtener más información concerniente a cada uno de los álbumes editados por el sello, se recurrió a la página oficial del mismo -que se encuentra bajo el dominio de

\footnotetext{
8:을 Depósito de la cinta reel en un contenedor mayor.

9o: Desecho de buzos de tyvek y guantes.

10: Desinfección de objetos no desechables.

11ㅇ: Desinfección de personas.

12으: Traslado del material al depósito.
} 
Portaldisc-, a los boletines Alerce informa (publicados entre 1995 y 2000) y al Gran Catálogo Alerce 1 (publicado en 1996).

En este inventario figuran el formato de los álbumes (en este caso CD) y su enumeración y su información básica (autor, título, año de publicación, serie, estilo, lugar y año de grabación y licencia).

En la columna "Expediente" se marcaron con una X todos los elementos encontrados (película, diapositiva, carátula, masters carátula, cover o cobertores de discos/casetes, afiches, volantes, gráfica o material gráfico contenido en disquetes, fotos, negativos y textos), siendo pertinente la especificación del tipo de material con el que se confeccionó el master de carátula (película, maqueta/diseño y/o disquete). A su vez, se marcó con una X en la columna "Expediente" si se encontró como mínimo un elemento gráfico asociado a cada álbum (exceptuando la carátula, que se guarda de modo aparte). Para la elaboración de los expedientes se siguió el orden de la enumeración de los álbumes, y se guardó todo el material asociado a dicho álbum en sobres de $36 \times 25 \mathrm{cms}$., los que a su vez fueron depositados en cajas enumeradas de 37 x 13,5 x 25 cms. En la planilla de los expedientes se incluyeron sólo las columnas vinculadas a los elementos gráficos de cada álbum, siendo la columna "Expedientes" la que sirve para informar la ubicación de la caja en donde se puede hallar el mismo.

Caso aparte son los elementos de los discos editados por Alerce en conjunto con otro sello discográfico, aquellos no asociados a ningún álbum en particular (o cuya fuente no se ha podido averiguar) y los de formato grande (por ejemplo, algunos afiches y masters de carátulas que no cupieron en los expedientes), todo lo cual se agrupó y guardó en cajas aparte. También las carátulas de casete y CD fueron archivadas en cajas separadas y ordenadas según la enumeración establecida por el sello, para su fácil consulta.

Como se insinuó en párrafos anteriores, la magnitud de documentación gráfica encontrada vinculada con información de prensa, ameritó que esta última fuera considerada un ítem específico en el procedimiento de inventario. El material estaba guardado en cajas de embalaje y consistía principalmente en recortes de prensa escrita, artículos de revistas, folletos, fotocopias, documentos y fotografías, todo en precario estado de conservación y con una leve capa de polvo que cubría el material. A pesar de esto, no se halló presencia de hongos o humedad evidente, aunque sí elementos metálicos como corchetes o clips, la mayoría en avanzado estado de corrosión, los que fueron eliminados 22.

\footnotetext{
21 Sello Alerce. Gran catálogo Alerce. Santiago: Alerce, 1996.

22 Tras retirar el contenido de las cajas, se realizó una revisión preliminar con el fin de facilitar el almacenamiento y la futura revisión por parte de personal especializado o de quien lo solicite. Según lo apreciado se adoptó la siguiente metodología de trabajo:

10: Separación de material según artista, grupo musical, personaje o evento.

2: Ordenación cronológica y por décadas, según la fecha de publicación original.
} 
Durante el periodo de clasificación del material, se apreció la meticulosidad por parte de quienes llevaban a cabo la labor de revisión de prensa a través de los años de la empresa. Esto porque no sólo se encontraron artículos referentes directamente al Sello Alerce o a Ricardo García, sino que también una serie de recortes de prensa relativos a otras temáticas, pero que estaban incluidos en el material porque en sus cuerpos -y aunque de manera muy breve- hacían mención a la casa discográfica, su fundador o algún artista o grupo que hubiese grabado con ellos. El material poseía, en la mayoría de los casos, la fecha y el nombre del medio en donde se publicó.

A medida que avanzó el proceso de revisión, se determinó otro rasgo de la rigurosidad con la que originalmente se archivó el material. Cada recorte de prensa se encontraba adherido a una hoja de papel blanco, tamaño carta y en la mayoría de los casos con el membrete del Sello Alerce, en el que se detallaban los datos de publicación. Además se encontraron fotocopias de los mismos artículos, en muchos casos con más de un respaldo.

De la superficie total de espacio utilizado por las cajas de la donación Sello Alerce en la sala del Archivo de Música, 130 centímetros lineales corresponden a las de prensa. De las tres cajas con material, que se ordenaron y clasificaron, se obtuvieron 77 sobres de papel y 4 carpetas con contenido en su interior. Éstos fueron colocados en ocho nuevas cajas de embalaje, para facilitar así su almacenamiento.

Tras los trabajos, de las cajas designadas como 1 y 2 resultaron 29 sobres y 4 carpetas con contenido de prensa. Éstos fueron guardados en seis cajas nuevas. Del material en la caja 3 (denominada "Prensa Alerce") resultaron 48 sobres que fueron guardados en dos cajas nuevas.

De los 48 sobres, destacaba uno con material documental de gran importancia. Éste posee información de difusión y referente al funcionamiento interno del sello discográfico: currículum y dosier de artistas y grupos, guiones de videoclips musicales, afiches y publicidad sobre eventos organizados por Alerce, entre otros.

Además llamó la atención la gran cantidad de recortes de prensa sobre el fundador del Sello Alerce, Ricardo García (1929-1990). Se clasificaron diez sobres de papel relacionados a este destacado locutor chileno. De los diez sobres, cinco

3o: Ordenación del contenido clasificado en sobres de papel debidamente rotulados y siguiendo la lógica: nombre y fecha.

4⿳⺈: Redacción de lista con los encabezados de cada sobre de papel, la que se adhirió a una caja de embalaje nueva.

5o: Almacenamiento de la documentación ordenada de manera cronológica, en la nueva caja de embalaje, siguiendo el orden de la lista de encabezados con el objetivo de facilitar futuras búsquedas.

6o: Guardado de caja con material ya clasificado en bodega a temperatura y humedad correctamente reguladas. 
correspondieron a su trayectoria profesional (1940-1990); uno a material de prensa sobre su muerte, funerales y homenajes póstumos, y cuatro sobres a recortes de prensa sin data.

Las cajas de prensa ya clasificadas fueron almacenadas a temperatura y humedad adecuada. Además, y en el intertanto del proceso, se seleccionaron algunos artículos de prensa para su digitalización y así poder complementar cápsulas web dentro del minisitio del Fondo Sello Alerce, en la plataforma Memoria Chilena de la DIBAM.

La información ofrecida por los documentos del fondo en desarrollo es sorprendentemente consistente. Si consideramos los criterios identificados por la musicóloga Sara Thornton (González, 2001) para el análisis de las experiencias musicales mediatizadas, la información que ofrecen los vestigios del conjunto documental contiene todos y cada uno de aquellos. La documentación contable y administrativa, que incluye balances, líneas de ventas y remesas, cubren el criterio "Nivel de consumo"; el "Nivel de mediatización" está sobradamente cubierto con la numerosa información de prensa; la documentación vinculada específicamente a Ricardo García y su familia constituyen el criterio "Interés biográfico", y "Aclamación crítica" está constituido por el análisis del sonido contenido en todos los soportes incluidos en el fondo documental. Ello implica que su estudio en conciencia permitiría aplicar las cuatro estrategias vinculantes a sus criterios, del estudio de la música popular. A saber: cuantificar, mediatizar, personalizar y canonizar.

Toda esta pequeña historia de rescate, ordenamiento, restauración, conservación, catalogación y sistematización de vestigios generados por el sello Alerce, ha permitido que fuentes derivadas de la historia musical chilena y su industria, estén disponibles para una comprensión de la historia del Chile reciente a través de una de sus expresiones culturales. Nuevas fuentes para la historia de Chile, esta vez generadas por un sello musical a través de su producción, su historia de vida y su experiencia social, han quedado finalmente disponibles para su estudio, como fragmentos de nuestro tiempo pasado.

\section{Palabras finales}

El Fondo Documental Sello Alerce es hoy en día uno de los acopios de documentos musicales más significativos a disposición del público e investigadores, para el estudio de la música popular chilena contemporánea. Razones hay muchas. Primero, es un fondo robusto. La cantidad de material que contiene es cuantitativa y cualitativamente consistente. Cuantitativa, pues está compuesto por miles de documentos; cualitativa, pues éstos responden a todas las características posibles de cómo la música popular se puede manifestar en una sociedad en el tiempo pasado. Esto implica que su soporte no necesariamente tiene que ser sonoro. La música 
también se manifiesta a través de imágenes, de textos, en fin, de todo aquello que pueda dar cuenta de experiencia social, y éste es el caso.

Segundo, es un fondo generado por la industria musical. Aquella característica de "mediatización" en la música popular, por ende, es constituyente de la formación de estos síntomas de pasado musical. La figura de su fundador Ricardo García y el papel que le cupo en la historia de la música chilena en los que posiblemente fueron los años más difíciles de desarrollo cultural -como lo fue el período de la dictadura de Pinochet- le dan al sello una singularidad que se transmite a sus documentos y los enriquece.

Tercero, final, lo más importante: es un cuerpo documental con historia. En su descubrimiento y recuperación estuvieron vinculadas historias de vida en que la música era el punto de convergencia. El arte era musical, la industria era lo mismo, la investigación era sobre música, el encuentro fue con un pasado sonoro. Fue más bien un reencuentro con el pasado desde una sensibilidad musical siempre presente, que esta vez se encontraba con el vestigio que daba luces sobre su original sentido. Fue el rescate de un cuerpo que se pensaba perdido y que ahora se podía ver, palpar, escuchar de nuevo. Un rescate de la historia a través de sus indicios, más que un rescate de la memoria.

Estas fuentes, así, no sólo nos hablan de la historia de la música en Chile; nos permiten comprender a través de su cualidad de fuentes musicales, parte de la historia social de nuestro país. No solamente nos dan la posibilidad de seguir escribiendo la historia social de la música popular chilena; nos permiten empezar a escribir, la historia musical de la sociedad chilena contemporánea.

\section{Bibliografía}

Araya, S. (2016): Aproximación a la producción discográfica en Chile (1973-1989). Nuevas prácticas y escuchas. Tesis de Magister en Musicología Latinoamericana, Universidad Alberto Hurtado, Santiago.

Astudillo, C. (2016): Documento de trabajo. Santiago, Dibam.

Cruz Mundet, J. R. (2003): Manual de Archivística. Madrid, Fundación Germán Sánchez Ruipérez.

Díaz, P. (2007): El Canto Nuevo Chileno. Un legado musical. Santiago, Universidad Bolivariana-Colección Cultura Popular.

Donoso, K. (2019): Cultura y dictadura. Censuras, proyectos e institucionalidad cultural en Chile, 1973-1989. Santiago, Ediciones Universidad Alberto Hurtado. 
Errázuriz, L. (2012): El Golpe Estético: Dictadura Militar en Chile 1973 - 1989. Santiago, Ocho Libros.

Fuenzalida, V. (1985): La industria fonográfica chilena. Santiago, Ceneca.

Gómez González, P. J. (ed.) (2008): El archivo de los sonidos: la gestión de fondos musicales. Santiago: ACAL.

González, J. P. y C. Rolle (2005): Historia social de la música popular en Chile. 18901950. Santiago, Ediciones Universidad Católica.

González, J. P. (2001): "Musicología popular en América Latina: síntesis de sus logros, problemas y desafíos", Revista. musical chilena, 55(195), pp. 38-64.

García, R. (1996): Ricardo García. Una obra trascedente. Santiago, s/e.

Moulian, T. (2002): Chile actual: anatomía de un mito. Santiago, Lom.

\section{Fuentes}

Alerce informa. Alerce: Santiago, 1995-2000.

Grupo Abril. Grupo Abril. Alerce, 1982. Casete.

Ortiga. Ortiga. Alerce, 1976. L.P.

Sello Alerce. 1996. Gran catálogo Alerce. Santiago: Alerce.

Santiago del Nuevo Extremo. A mi ciudad. Alerce, 1981. Casete.

Fecha de recepción: 11 de abril de 2021

Fecha de aceptación: 2 de junio de 2021 